\title{
A Política do Brasil para as Migrações Internacionais*
}

Rossana Rocha Reis**

\section{Introdução}

Em meados dos anos 1980, a percepção da emergência de um fluxo contínuo de brasileiros fixando residência em outros países surpreendeu o país. Historicamente, sobretudo entre o final do século XIX e início do século XX, e posteriormente, entre os anos 1920 e 1930, o Brasil foi o destino de centenas de milhares de migrantes, principalmente europeus e japoneses, em busca de um futuro mais próspero. A mudança provocou um abalo na autoimagem de "país de imigrantes" cultivada até então, e foi retratada pelos jornais e pela televisão como mais um sintoma do fracasso do país em atender as grandes expectativas referentes ao seu desenvolvimento econômico e social.

Os primeiros estudos conduzidos sobre o tema da emigração de brasileiros apontavam a desilusão com os rumos do país pósredemocratização como uma das razões do fenômeno (SALES, 1999). Os migrantes se dirigiam então majoritariamente para os Estados Unidos, referência universal de prosperidade, e também para Portugal, Itália e Japão, países ligados ao Brasil por correntes migratórias anteriores (PATARRA, 1996). Recentemente, os brasileiros têm diversifi-

* Artigo recebido em 28 de fevereiro de 2011 e aprovado para publicação em 25 de julho de 2011.

** Pós-doutora pela Universidade de Harvard, professora do Departamento de Ciência Política e do Instituto de Relações Internacionais da Universidade de São Paulo (USP), e autora do livro Políticas de imigração nos Estados Unidos e na França (São Paulo: Hucitec, 2007). E-mail: rossanarr@uol.com.br. 
cado cada vez mais os seus locais de destino pelo mundo, como mostram as estimativas do Ministério de Relações Exteriores (MRE) em 2008, e o Perfil migratório do Brasil 2009, publicado pela Organização Internacional para as Migrações (OIM) em 2010.

A emigração contemporânea também é alimentada por outro fluxo bastante significativo e anterior aos acima descritos, o de brasileiros em direção ao Paraguai na década de 1970, cuja lógica está diretamente relacionada à expansão da fronteira agrícola brasileira, sobretudo ao cultivo da soja e à criação de gado, e também à própria política paraguaia de atração de imigrantes. De fato, os brasileiros estão hoje não apenas no Paraguai, mas também espalhados em diversos outros países vizinhos, em busca de possibilidades abertas não só pela agricultura, mas pelo garimpo e pelo comércio.

No total, em 2008, o Ministério das Relações Exteriores estimava que houvesse entre 2.059.623 e 3.735.826 de brasileiros no exterior (MRE, 2008). Por outro lado, nos últimos anos, a estabilização econômica e o crescimento voltaram a tornar o Brasil um país atraente para imigração, e passamos a ser o local de destino de imigrantes de países vizinhos, como a Bolívia, e também de grupos vindos de países mais distantes, como os chineses, que já somam 250 mil no Brasil. Embora o saldo migratório atual seja ainda francamente favorável a emigração, a imigração vem crescendo, e em 2009 a OIM estimava em 688.026 o número de imigrantes no Brasil, embora grande parte dos analistas trabalhe com um contingente de pelo menos 1 milhão de estrangeiros no Brasil, contando com os indocumentados.

O objetivo deste artigo é reconstruir em linhas gerais a maneira como o Estado brasileiro vem se posicionando em relação ao tema das migrações internacionais, e analisar o seu comportamento frentes aos fluxos migratórios contemporâneos que envolvem o país. De um modo geral, veremos que ao longo dos últimos vinte anos surgiram diversas iniciativas em relação à emigração. Veremos também um investimento nas políticas voltadas para a gestão das migrações nas fronteiras, que está diretamente relacionado ao projeto de integração regional do Brasil. No campo das políticas voltadas para os imigrantes estran- 
geiros no Brasil, no entanto, as mudanças são menos acentuadas, ainda que tenha havido três anistias e que atualmente estejam em curso projetos para alterar a legislação sobre o assunto.

Nossa hipótese é que o tratamento dado à questão migratória pelo Estado brasileiro está relacionado não apenas ao importante ativismo de migrantes e seus aliados, como veremos mais adiante neste artigo, mas também a um objetivo mais amplo no plano internacional, sobretudo ao longo do governo Lula. A maneira de compreender e lidar com as migrações internacionais tem relação direta com o objetivo de defender e assegurar o protagonismo do país em fóruns regionais e multilaterais, dentro de um contexto internacional em que o tema é cada vez mais importante e controverso. Nesse sentido, podemos caracterizar a política em relação aos emigrantes, e também aquelas de cunho regional, como formas de política externa. Nos últimos anos, mesmo a política de imigração começou a ser percebida como parte importante da posição do Brasil em relação às migrações no plano internacional, o que explica as mudanças que estão sendo propostas no sentido de tornar mais coerente a posição do país em relação às migrações no sentido mais amplo.

$\mathrm{O}$ artigo está dividido em quatro partes. Na primeira, exploramos as políticas do Estado brasileiro para os brasileiros no exterior. Na segunda, o que chamamos de políticas de dupla face, ou seja, aquelas que envolvem não apenas o Brasil, mas também outros países, e que atingem tanto os emigrantes brasileiros, como os imigrantes no Brasil, em particular aquelas que se relacionam com o processo de integração regional. $\mathrm{Na}$ terceira parte, tratamos das políticas para os imigrantes no Brasil. Desde já, adiantamos que essa divisão é em alguma medida arbitrária, já que em muitas situações os três tipos de política se sobrepõem. Finalmente, procuramos compreender a relação entre a atuação do Brasil no que diz respeito às migrações internacionais e as diretrizes do posicionamento do Brasil no plano internacional. De fora do âmbito dessa análise, ficam as políticas voltadas para os refugiados e o tema do tráfico de seres humanos, que merecem mais atenção e destaque do que seria possível neste artigo. 


\section{O Estado brasileiro e seus emigrantes}

A relação do Estado brasileiro com os brasileiros no exterior modificou-se consideravelmente de meados da década de 1980 para cá. Se no início, o Ministério das Relações Exteriores do Brasil dedicava pouca atenção a eles, com o passar do tempo várias medidas foram tomadas para fortalecer os laços dos emigrantes com o Estado brasileiro.

No plano institucional, a primeira medida de importância para os brasileiros no exterior se deu em 1995, quando o então ministro das Relações Exteriores, Fernando Henrique Cardoso, implementou o Programa de Apoio aos Brasileiros no Exterior, que consistia basicamente na criação dos chamados "consulados itinerantes" para atender a regiões nas quais a presença brasileira vinha crescendo. Em Brasileiros longe de casa, a socióloga Teresa Sales (1999) destaca a importância dessa iniciativa para impulsionar a organização dos brasileiros na cidade de Boston em meados dos anos 1990. Os consulados itinerantes continuam a funcionar. Só no ano passado, de acordo com o MRE (s/d): "Foram realizados ao longo de 2010, pela rede consular brasileira, um total de 284 consulados itinerantes, espalhados em 21 países; 159 cidades, com atendimento de um total de 33.898 nacionais brasileiros e processamento de 37.109 documentos diversos."

Em 1996, outra mudança significativa na legislação reconhecia a importância da emigração brasileira e a necessidade de garantir aos brasileiros estabelecidos em outros países a manutenção dos seus laços com o Brasil e dos seus direitos como cidadãos. A introdução da possibilidade da dupla cidadania era uma reivindicação importante dos emigrados brasileiros, que estavam começando a estabelecer famílias no exterior.

Desde os anos 1990, os brasileiros espalhados pelo mundo têm se organizado para reivindicar seus direitos e políticas de apoio por parte do Estado brasileiro. ${ }^{1}$ De acordo com dados compilados pelo MRE, em 2009 existiam "356 associações e organizações de brasileiros em 45 países, além de 216 veículos de mídia a eles dirigidos" (FUNAG, 
2009, 13). O MRE, por sua vez, recentemente, tem se interessado mais pela experiência de países que possuem políticas mais abrangentes e proativas em relação aos seus cidadãos residentes no exterior. A percepção de que a manutenção dos laços dos emigrantes com o país é importante não apenas para os indivíduos envolvidos no processo, mas para o próprio país, parece estar na base desse movimento.

Em termos econômicos, a tomada de consciência, por parte do Estado brasileiro, da importância das remessas dos brasileiros no exterior foi sem dúvida um fator que contribuiu para tornar o Estado brasileiro mais sensível às demandas desses grupos e mais interessado na manutenção dos laços que ligam os emigrantes ao Brasil. Estimativas do Banco Interamericano de Desenvolvimento para 2005 são da ordem de US\$ 6,4 bilhões. Com a crise econômica norte-americana, esses números caíram, mas as remessas continuam sendo uma importante fonte de divisas internacionais para o país. O Perfil migratório do Brasil 2009 estima que o Brasil seja "o segundo maior receptor de remessas da América latina, atrás somente do México, com valores que ultrapassam USD 5,0 bilhões anuais. Se por um lado este volume de remessas tem certa importância em algumas cidades para o desenvolvimento local, no plano macro elas representam menos de $1 \%$ do PIB nacional" (OIM et al., 2010, p. 10).

Também não podemos esquecer que os emigrantes votam. De fato, o número de votantes cadastrados no exterior tem crescido a cada eleição. Entre a eleição de 2006 e a atual, esse número cresceu 132\%, saltando de 86.255 em 2006 para 200.392. Se pensarmos em relação a 1989, o primeiro ano de eleições diretas para presidente no Brasil depois do regime militar, o crescimento é de quase $1.000 \%$. Esse número representa apenas $0,148 \%$ do total de eleitores no Brasil (135.604.041), no entanto, "dado que o sistema eleitoral brasileiro permite uma segunda volta, no caso hipotético de uma eleição muito renhida, $1 \%$ de potenciais eleitores poderiam definir os resultados, pelo que o voto dos emigrantes é parte integrante da aritmética política nacional" (CHELIUS, 2007, p. 205).

Atento a esse público, em 2002, o então candidato à Presidência do Brasil, Luiz Inácio Lula da Silva, divulgou a Carta aos brasileiros lon- 
ge de casa", na qual incorporava à sua plataforma de campanha um conjunto de propostas políticas como a redução da taxa para remessas e a melhora do atendimento consular para brasileiros no exterior. Também em 2002 foi realizado, em Portugal, o I Encontro Ibérico da Comunidade de Brasileiros no Exterior, promovido pela Procuradoria Regional de Direitos do Cidadão do Distrito Federal, com a participação de emigrantes, políticos, religiosos e pesquisadores, que articularam as demandas dos emigrantes brasileiros no que ficou conhecido como Documento de Lisboa.

O Documento demandava, entre outras coisas, a criação de um grupo de trabalho interministerial para tratar da emigração, a "Criação de uma Secretaria ou Departamento com poderes jurídicos no âmbito do Ministério da Justiça e do Ministério das Relações Exteriores para os assuntos de emigração", de um mecanismo de representação dos emigrantes brasileiros, de comissões no Congresso Nacional para tratar de "questões específicas de interesse dos brasileiros no exterior", além da manutenção e ampliação dos consulados itinerantes e uma série de medidas visando a garantia dos direitos civis, políticos, culturais, econômicos e sociais dos emigrantes brasileiros.

A favor da atuação das organizações de apoio aos emigrantes, estava a crescente sensibilidade da opinião pública doméstica ao tema da discriminação de brasileiros no exterior. Episódios recentes, como o assassinato de Jean Charles Menezes pela polícia inglesa em Londres, e acusações de maus-tratos por agentes da imigração em aeroportos da Europa recebem um grande destaque na mídia brasileira. ${ }^{3}$ Não por acaso, entre 2005 e 2006 funcionou uma Comissão Parlamentar de Inquérito Mista, com o objetivo de "apurar os crimes e outros delitos penais e civis praticados com a emigração ilegal de brasileiros para os Estados Unidos e outros países, e assegurar os direitos de cidadania aos brasileiros que vivem no exterior".

A Comissão participou do Encontro de Lideranças Brasileiras nos Estados Unidos, no qual foi elaborada a Carta de Boston, contendo as reivindicações dos emigrantes brasileiros ao governo e ao Congresso, entre as quais também estavam a ampliação dos consulados itinerantes, o maior envolvimento dos consulados na organização das comu- 
nidades de brasileiros nos Estados Unidos e o empenho do governo brasileiro em negociações bilaterais com o Estado norte-americano a fim de garantir mais vistos de reunificação familiar e de trabalho, apoio jurídico a emigrantes presos, entre outras demandas.

A CPI adotou em suas recomendações muitas das propostas do Documento de Lisboa, e da Carta de Boston, que estão sendo, em parte, implementadas pelo governo brasileiro. Em dezembro de 2006, o governo brasileiro criou uma Subsecretaria-geral para as Comunidades Brasileiras no Exterior, "com atribuições de cuidar dos temas relativos aos brasileiros no exterior e aos estrangeiros que desejam ingressar no Brasil, incluindo-se a cooperação judiciária internacional" (AMORIM, 2009). Criaram-se também sites na Internet para facilitar a vida dos emigrantes brasileiros: o Portal Consular, o Portal das Comunidades e também uma Ouvidoria Consular (2009). No ano passado, com o aumento dos brasileiros retornando ao Brasil, impulsionados pela crise econômica que atingiu fortemente os Estados Unidos, o Japão e muitos países da Europa, a Secretaria também disponibilizou um guia aos repatriados, que também era uma reivindicação dos brasileiros no exterior.

Acordos bilaterais na área de previdência social foram assinados com diversos países, como Chile, Japão, Estados Unidos e Alemanha. Por outro lado, em 2010, a Caixa Econômica Federal definiu as condições para que os emigrantes possam retirar o Fundo de Garantia no Japão, e está estudando um projeto semelhante para os brasileiros nos Estados Unidos. O tema também esteve presente em encontros bilaterais com Portugal, França, Paraguai, entre outros.

Em 2008, pela primeira vez, no Palácio do Itamaraty do Rio de Janeiro, realizou-se a Conferência Brasileiros no Mundo. Em 2009, na segunda conferência, foi sugerida a criação do Conselho de Representantes Brasileiros no Exterior (CRBE). Ainda nesse ano, a sugestão foi incorporada ao Decreto Presidencial 7.214, que também estabeleceu as diretrizes da política governamental para os brasileiros no exterior, determinou a periodicidade anual para a Conferência Brasileiros no Mundo e formulou a Ata Consolidada de Demanda das Comunidades, elaborada a partir das reivindicações presentes nas duas primeiras con- 
ferências, como "roteiro para os órgãos públicos prestarem contas a respeito de suas ações que beneficiam os brasileiros no exterior". 5

Em 2010, a III Conferência Brasileiros no Mundo contou com a presença do presidente da República e de oito ministros de Estado, deputados, senadores, governadores e outras autoridades. Também participou da Conferência o recém-empossado CRBE, formado por quatro representantes de cada uma das regiões do mundo (Américas do Sul e Central, América do Norte e Caribe, Europa, Ásia, África, Oriente Médio e Oceania). Os membros do CRBE foram escolhidos por meio de uma consulta realizada pela Internet, entre $1^{\circ}$ e 9 de novembro de 2010, para preencher as vagas do recém-criado conselho, que tem caráter consultivo, devendo trabalhar junto com a Subsecretaria-geral das Comunidades Brasileiras no Exterior.

O representante dos brasileiros na Suíça Ocirema Kukleta considerou a Conferência de 2010 um momento histórico. Em suas próprias palavras:

O Itamaraty começou a enxergar que existem brasileiros fora. Nunca considerou o público que está fora, mas agora está considerando. Essa mudança de comportamento, mesmo não acontecendo sempre nem por parte de todos, está em andamento. Existe uma marcha de todas as pessoas engajadas para que aconteça essa mudança política. No primeiro encontro europeu que nós tivemos - com 77 pessoas de onze países - o MRE sequer compareceu. Hoje, estamos aqui com o presidente, com ministros, com o governador e o prefeito do Rio. Vejo que esse peso político é uma grande conquista. (ITAMARATY..., 2010)

As organizações de brasileiros no exterior têm uma agenda mais ambiciosa no que concerne à relação dos emigrantes com o Estado brasileiro, que inclui a representação dos brasileiros emigrantes no Con- 
gresso Nacional ${ }^{6}$ e a criação de uma secretaria de emigração, ${ }^{7}$ vinculada diretamente à Presidência, e de preferência ocupada por alguém com experiência migrante. Atualmente, a gestão das políticas para os emigrantes acaba passando não apenas pelo MRE, mas também por outros Ministérios envolvidos na questão, como o Ministério da Justiça, o do Trabalho e do Emprego, e o da Previdência Social. O próprio Conselho Nacional de Imigração (CNIg), cujas atribuições originalmente dizem respeito somente à imigração para o Brasil, também está com frequência envolvido no debate sobre a emigração. No momento, tramita no Congresso um projeto de lei que transforma o órgão em Conselho Nacional de Migração, aumentado suas atribuições formais em relação aos emigrados. Trataremos do projeto com mais detalhes quando discutirmos a política para os imigrantes no Brasil.

\section{Políticas de dupla face}

Políticas de dupla face são aquelas que estão voltadas para uma gestão conjunta da questão da migração, entre país receptor e país emissor, sobretudo quando, como é o caso entre Brasil e Paraguai, existem fluxos em mais de uma direção. Historicamente, o Brasil teve acordos importantes com Portugal, como o Tratado Bilateral de Igualdade de Direitos, firmado em 1972, e o Tratado de Amizade, Cooperação e Consulta entre a República Federativa do Brasil e a República Portuguesa, em 2001. Recentemente, o foco desses acordos é principalmente a América do Sul.

O interesse do Estado brasileiro em políticas específicas voltadas para os emigrantes em países vizinhos deve-se, em grande medida, às implicações desses fluxos para as relações bilaterais e para a política de integração regional do Brasil. De um modo geral, essa migração tem um perfil muito diverso daquele que vai para os Estados Unidos, Europa e Japão: são menos organizados, têm menos recursos e exigem políticas de caráter bastante específico. Só no Paraguai, segundo as estimativas do MRE (2008), existem entre 204.890 e 515.517 brasileiros. Na Bolívia, entre 13.774 e 46.600 brasileiros. Na fronteira norte do país, entre 39.487 e 127.106 brasileiros, dos quais uma grande parte são garimpeiros, distribuídos entre a Bolívia, as Guianas, a Venezu- 
ela, a Colômbia e o Suriname (MRE, 2008). Para lidar com a gestão das fronteiras, o Estado brasileiro tem atuado de três formas diferentes: por meio de acordos multilaterais amplos, como os que preveem a livre circulação entre os países membros do Mercosul + Chile e Bolívia; por meio de acordos bilaterais; e por meio de políticas localizadas, dirigidas para cidades das fronteiras.

A presença de brasileiros nos países vizinhos tem gerado diversas formas de tensões sociais. No Paraguai, a maior parte dos brasileiros são trabalhadores rurais, grandes e pequenos proprietários de terra, muitos deles em situação de insegurança jurídica. Entre as suas reivindicações ao Estado brasileiro, está principalmente a regularização de documentos e a garantia de acesso aos serviços do Estado de bemestar brasileiro nas cidades das fronteiras. Além disso, há problemas e controvérsias relativas à propriedade de terra que remontam ao governo do presidente Stroessner e que alimentam os conflitos com os paraguaios. De acordo com o Relatório da CPI da Emigração, a relação entre os dois grupos não é pacífica:

Há vários incidentes no campo, incluindo queima de plantações e furto de casas de brasileiros. O conflito agrário não é restrito aos brasileiros, pois se estende também a latifundiários paraguaios, principalmente os militares favorecidos por Stroessner, e a outros estrangeiros. Com brasileiros, entretanto, existem conflitos específicos, como os relacionados aos danos ambientais provocados pelo uso do solo, ao confronto político com prefeitos brasileiros e a tensões com a polícia local. (REPÚBLICA FEDERATIVA DO BRASIL, 2006, p. 312)

Na Bolívia, o envolvimento de brasileiros na exploração de terras perto da fronteira com o Brasil também tem sido fonte de conflitos. A Constituição boliviana determina que os estrangeiros não podem adquirir ou ocupar terras em uma faixa de $50 \mathrm{~km}$ ao longo da fronteira. A disposição do governo boliviano em fazer cumprir a Constituição 
atingiu diretamente um grupo de pelo menos quatrocentas famílias de brasileiros estabelecidas na região e tornou-se o foco de tensões locais e negociações bilaterais entre os dois países. Em março de 2010, uma ação conjunta dos Ministérios das Relações Exteriores e do Desenvolvimento Agrário com o apoio do Instituto Nacional de Colonização e Reforma Agrária (INCRA), do estado do Acre e de prefeituras, em contato com o Ministério das Relações Exteriores da Bolívia, tomou medidas para assentar ao menos 150 dessas famílias no Acre.

As tensões na fronteira Norte estão relacionadas quase sempre ao avanço do garimpo. No Suriname, no final de 2009, os brasileiros estavam entre o grupo de estrangeiros agredidos violentamente na cidade de Albina por um grupo de descendentes de quilombolas descontentes com sua presença e com a exploração do garimpo na região. A Guiana Francesa, de acordo com o relatório da CPI da Emigração, "é o território que individualmente mais promove a repatriação, deportação e expulsão de brasileiros, tendo registrado, em 2004, 5.824 dessas ocorrências" (REPÚBLICA FEDERATIVA DO BRASIL, 2006, p. 29).

Sem dúvida, o mais importante aspecto recente das políticas de dupla face são as iniciativas voltadas para a criação de uma área de circulação livre na América do Sul, e também para a garantia de direitos de cidadania para os migrantes dentro da região. ${ }^{8}$ A proposta de integração regional da América do Sul incluiu desde o princípio a perspectiva da criação de um espaço de livre circulação, contudo, a demora entre a assinatura do Acordo de Residência do Mercosul, e do Acordo Mercosul + Bolívia e Chile, em 2002, e sua entrada em vigor, em 2009, sugerem que o tema é mais controverso do que parece à primeira vista.

O Acordo de Residência do Mercosul, Bolívia e Chile permite aos nacionais desses países residirem e trabalharem no Brasil por dois anos com status provisório, e depois disso solicitarem status de permanente, dispondo

[...] ainda sobre os direitos dos imigrantes e de suas famílias, estabelecendo a igualdade de direitos civis no país de recepção; a promoção da reunião familiar; a igualdade de tratamento com 
os nacionais do Estado de residência; compromisso com os direitos previdenciários adquiridos no outro país; direito de transferir recursos; e o direito de nome, registro e nacionalidade aos filhos desses imigrantes (apud MILESI; BARBOSA, 2009).

O avanço legislativo encobre a permanência de manifestações de xenofobia e discriminação contra imigrantes latino-americanos, que seguem sendo um problema no Brasil e nos países vizinhos, como atestam diversas matérias nos jornais, assim como os trabalhos de sociólogos e antropólogos da região. Mesmo assim, a mudança legislativa é importante para combater a insegurança jurídica que prejudica sobremaneira a vida dos migrantes na região. A partir da ratificação do acordo, Brasil e Paraguai deram início a negociações bilaterais que já beneficiaram diretamente milhares de migrantes. Segundo informativo do MRE:

No dia 3 de maio em Ponta Porã (MS), os presidentes Luiz Inácio Lula da Silva e Fernando Lugo, por ocasião do encerramento do encontro presidencial, fizeram entrega simbólica de carnês de residência temporária a paraguaios em situação migratória irregular no Brasil e a brasileiros nas mesmas condições residentes no $\mathrm{Pa}$ raguai. O presidente Lula entregou em mãos de três cidadãos do país vizinho os documentos emitidos com base na Lei da Anistia. Em contrapartida, família de três brasileiros (pai, mãe e filho menor) recebeu do mandatário paraguaio os carnês de residência temporária do programa de regularização de brasileiros no Paraguai, negociado com fundamento nos Acordos de Residência do Mercosul, cujos respectivos instru- 
mentos de depósito foram confirmados pelo $\mathrm{Pa}$ raguai em julho de 2009. (MRE, 2010).

\section{Os imigrantes no Brasil}

Atualmente, acredita-se que entre 600 mil e 1 milhão de estrangeiros vivem no Brasil. O número é baixo, considerando a dimensão total da população brasileira, mas a concentração de alguns grupos em cidades específicas vem contribuindo para uma maior visibilidade do tema migração na sociedade brasileira. As comunidades de bolivianos e chineses na cidade de São Paulo e os libaneses em Foz do Iguaçu são alguns casos emblemáticos. A "lei de estrangeiros" que regula a entrada e permanência de imigrantes no Brasil foi criada em 1980, ainda na vigência do regime ditatorial no Brasil e se insere na lógica da "segurança nacional" do período. A elaboração dessa lei se deu em um momento em que o regime militar estava particularmente descontente com a "interferência" de religiosos estrangeiros em assuntos considerados de foro interno e buscava um mecanismo que facilitasse a expulsão de estrangeiros envolvidos em atividades políticas no país. De fato, a Igreja Católica no Brasil foi desde o início uma das principais críticas da legislação brasileira para estrangeiros, e segue hoje sendo a base para muitas das organizações de defesa dos interesses e dos direitos dos estrangeiros no Brasil.

A principal crítica das organizações que defendem os interesses dos imigrantes no Brasil diz respeito ao fato de que muitas das disposições presentes na lei de 1980 estão em flagrante descompasso com as disposições relativas ao respeito dos direitos humanos presentes na Constituição de 1988 (ACNUR et al., 2007). A inconsistência da legislação de 1980 é apontada como um ponto fraco das demandas do Estado brasileiro para tratar a questão dos emigrantes brasileiros em negociações e fóruns bilaterais e multilaterais.

Os movimentos sociais, organizações não governamentais e pesquisadores no Brasil ao longo dos anos buscaram não apenas sensibilizar o Estado brasileiro para as demandas dos emigrantes estrangeiros, como também construir um consenso sobre a importância das mudanças na lei de imigração brasileira e sua conexão com as demandas dos brasileiros 
no exterior. A carta enviada pelo coordenador do Centro de Apoio ao Migrante de São Paulo, Paulo Illes, para a candidata Dilma Rousseff em outubro de 2010 é bastante ilustrativa desse argumento:

[...] ao defender uma política de migração integral, a qual contempla tanto as migrações de brasileiros e brasileiras para o exterior, o retorno de emigrantes e a imigração em nosso país, sempre sob o enfoque dos direitos humanos, percebemos a necessidade da construção de uma Secretaria de Políticas Migratórias, vinculada ao Gabinete da Presidência da República que possa articular e promover a implementação de uma política migratória coordenada entre estes órgãos e outros da administração pública.

[...] Superando-se a dispersão de competências que por vezes dificulta o avanço, uma das principais tarefas desta nova instituição seria, sem dúvida, fortalecer ainda mais a postura do Brasil como um país exemplo de acolhida para imigrantes e livre da discriminação e da xenofobia.

Em termos institucionais, a movimentação de pessoas através das fronteiras do Brasil envolve um conjunto variado de Ministérios e autarquias: o Ministério das Relações Exteriores, o Ministério do Trabalho, o Ministério da Justiça, a Polícia Federal, entre outros. Em princípio, o órgão que coordena as ações dessas diversas instituições em relação à entrada de estrangeiros no país é o Conselho Nacional de Imigração (CNIg), criado pela lei de 19 de agosto de 1980 e vinculado ao Ministério do Trabalho, e que tem por objetivo, entre outros, "formular a política de imigração", "coordenar e orientar as atividades de imigração", fazer um levantamento das necessidades do mercado de trabalho no Brasil, realizar estudos, coletar informações e "opinar sobre alteração de legislação relativa à imigração quando proposta por qualquer órgão do governo executivo" (PRESIDÊNCIA DA REPÚBLICA, 1993). 
O debate sobre a necessidade de transformar a legislação de estrangeiros infelizmente tem pouca repercussão. Em 2009, finalmente, o governo encaminhou para o Congresso a proposta do Novo Estatuto dos Estrangeiros (PL 5.655/2009). Entre outras mudanças, a lei prevê a transformação do CNIg em Conselho Nacional de Migrações, estendendo formalmente sua competência a questões que dizem respeito à emigração de brasileiros.

Também é importante destacar que três anistias foram realizadas no Brasil, a primeira em 1988, depois em 1998 e finalmente em 2009. Nesta última, 43 mil estrangeiros foram regularizados, entre os quais 17 mil bolivianos e mais de 4 mil paraguaios. Se, por um lado, as anistias demonstram a "boa vontade" oficial para lidar com a questão dos indocumentados, por outro lado revelam a persistência do problema ao longo dos anos e a necessidade de uma política mais abrangente. Idealmente, com a implementação dos acordos de livre circulação e a nova legislação de estrangeiros, o número de indocumentados no país deve cair.

\section{Migrações e política externa}

As mudanças positivas na relação entre o Estado brasileiro e seus migrantes se devem em grande medida ao ativismo dos próprios migrantes, como pudemos ver até aqui. Em termos da emigração brasileira, isso se traduziu na criação de canais institucionais de comunicação entre o Estado e os emigrantes, na melhora do atendimento consular e em medidas para facilitar o envio de remessas, entre outras. A importante contribuição financeira dos emigrantes, sua participação política e a repercussão de casos de discriminação contra brasileiros no exterior sem dúvida contribuíram para tornar o Estado mais sensível às demandas do grupo.

Outro fator importante, embora menos destacado pela literatura, é a percepção das migrações internacionais como um tema estratégico nas relações internacionais no século XXI. Como atesta a literatura recente sobre migrações, o aumento na circulação de pessoas é uma característica incontornável do mundo contemporâneo, de modo que a administração das tensões e dos conflitos que surgem a partir dessa circulação 
se coloca como uma das grandes questões políticas do nosso tempo. É nesse contexto que as escolhas do Brasil em termos de migração crescem em importância, mesmo que a dimensão dos fluxos migratórios que envolvem o país não seja tão expressiva, especialmente se comparada aos maiores receptores e emissores de população do mundo.

Acreditamos que a importância internacional do tema das migrações contribuiu para que fosse bem-sucedida a campanha dos grupos imigrantes e de apoio aos imigrantes para promover mudanças na legislação brasileira (com a ressalva de que a nova legislação de estrangeiros ainda não foi votada pelo Congresso). Há pelo menos vinte anos, esses grupos vêm defendendo a tese de que, para exigir um tratamento mais digno e em consonância com princípios de direitos humanos aos emigrantes brasileiros no exterior, era necessário antes de tudo oferecer o mesmo tratamento aos emigrantes no Brasil. Ao argumento de cunho moral, veio juntar-se a percepção de ganhos bastante concretos. Em um contexto em que a atuação externa do Brasil em termos de direitos humanos sofre críticas em fóruns domésticos e internacionais, a gestão da questão migratória ofereceu ao governo brasileiro, ao longo dos últimos anos, uma plataforma única para criticar o posicionamento dos países ricos. Assim, em sua fala no Conselho de Direitos Humanos na ONU em junho de 2009, o presidente Lula destacou os efeitos perversos da crise econômica sobre os migrantes, criticou o crescimento de manifestações xenófobas na esteira da crise e destacou que: "No Brasil, nós acabamos de legalizar centenas de milhares de imigrantes que viviam ilegalmente no país. Para dar uma resposta, um sinal aos preconceituosos, aqueles que imediatamente querem encontrar os responsáveis pela sua própria desgraça, o seu desemprego." (LULA..., 2009a).

Da mesma forma, no dia $1^{\circ}$ de julho de 2009 , quando anunciou a mais recente anistia aos imigrantes indocumentados no Brasil e enviou o projeto de reforma da lei dos estrangeiros ao Congresso Nacional, o presidente Lula publicamente solicitou ao ministro da Justiça que levasse o tema à reunião do G8 para, em suas palavras, "mostrar aos líderes dessas grandes economias a contrariedade do Brasil com a política dos ricos com os imigrantes" (LULA..., 2009b). Ainda na mes- 
ma solenidade, o presidente brasileiro afirmou: "Trabalho e dignidade para o imigrante é a resposta que o Brasil dá à intolerância dos países ricos".

Trazer o tema das migrações, e mais especificamente a questão dos direitos humanos dos imigrantes, para os fóruns internacionais reforçou as diretrizes mais amplas da política externa brasileira, que nos últimos oito anos tem buscado questionar a hierarquia internacional dentro de organismos multilaterais, fortalecer a cooperação Sul-Sul e denunciar "dois pesos e duas medidas" em relação a temas como direitos humanos e desenvolvimento. De um modo geral, diante da crescente securitização da matéria nas políticas da União Europeia e dos Estados Unidos, o Brasil tem procurado marcar a sua posição denunciando a discrepância entre o discurso de direitos humanos desses blocos e países, e o tratamento que tem sido oferecido por eles aos imigrantes. Ao mesmo tempo, o país reivindica uma posição unificada sobre o assunto para os países do Sul e um papel de vanguarda na defesa dos direitos humanos dos imigrantes. Dentro dessa estratégia, o governo brasileiro juntou-se a outros governos sul-americanos na condenação veemente da diretiva de retorno aprovada pela União Europeia em junho de 2008, que o presidente Lula classificou em discurso como "uma odiosa perseguição aos latino-americanos". 9 Na mesma linha, na abertura do Terceiro Fórum Mundial da Aliança das Civilizações, promovido pela ONU no Rio de Janeiro em maio de 2010, mais uma vez utilizou o endurecimento das políticas em relação à imigração nos países ricos como um dos argumentos para a crítica da ordem mundial: "Incapazes de assumir seus próprios erros, alguns governantes buscam transferir o ônus da crise para os mais fracos. Adotam medidas protecionistas que oneram bens e serviços exportados para países em desenvolvimento. Ao mesmo tempo, se mostram lenientes com os paraísos fiscais e responsabilizam imigrantes pela crise social" (apud ABDALA, 2010).

Em 2009, o Brasil assinou a Convenção Internacional sobre os Direitos dos Trabalhadores Migrantes e Membros de suas Famílias. Em dezembro de 2010, o governo brasileiro enviou para o Congresso o pedido de ratificação da Convenção. Na carta dirigida ao presidente da 
República, o ministro das Relações Exteriores Celso Amorim (2009) justifica a necessidade de ratificação por parte do Brasil nos seguintes termos:

Em contexto de restrição cada vez maior da entrada, permanência e garantia dos direitos dos migrantes, a ratificação da Convenção pelo Brasil representaria fortalecimento de sua posição favorável à defesa da proteção dos direitos humanos, daria maior legitimidade a seu papel em foros internacionais sobre direitos dos migrantes e poderia ser estímulo ao processo de universalização da ratificação deste importante instrumento de direitos humanos.

Se a retórica brasileira em termos de migrações é importante no âmbito multilateral, é sem dúvida no âmbito da integração regional que a posição do Brasil vem produzindo resultados mais concretos. Ao longo do desenvolvimento do processo de integração, a migração tanto poderia fornecer argumentos contra a ideia da livre circulação, e ser utilizada como um fator disruptivo nas relações entre o Brasil e seus vizinhos, como poderia ser interpretada e utilizada como uma espécie de catalisador do processo de integração. Em termos gerais, parece claro que a opção do Brasil e seus vizinhos tem sido tratar a gestão da migração regional da segunda maneira.

Evidentemente, esse não é um processo fácil. Pelo contrário, é carregado de contradições, desentendimentos e tensões, que envolvem interesses estatais distintos e pressões de diversos grupos sociais e políticos atingidos mais ou menos diretamente pelas migrações, sobretudo nas zonas de fronteira. Também é importante analisar as políticas voltadas para a circulação de pessoas não apenas de forma isolada, mas em conjunto com outras ações e temas relacionados à gestão de fronteiras, como o combate ao narcotráfico, às guerrilhas e ao contrabando, para aprofundar a avaliação sobre a política do Brasil para suas fronteiras. No momento, ainda estamos por ver quais serão os resultados de médio e longo prazo da ratificação dos acordos de livre circu- 
lação entre os países do Mercosul, Bolívia e Chile. Estamos também aguardando a aprovação da nova legislação de estrangeiros, que é um passo fundamental na direção de uma política de respeito aos direitos humanos dos imigrantes.

Finalmente, precisamos estar atentos ao recrudescimento de manifestações xenófobas e do preconceito contra estrangeiros, sobretudo africanos e latino-americanos nas cidades onde a sua presença se tornou mais visível. Em São Paulo, são frequentes os relatos de extorsão, discriminação na escola, péssimas condições de trabalho e discriminação no acesso a serviços públicos. É necessário ter em mente que, mantido o atual processo de crescimento econômico e considerando o desenrolar do processo de integração regional, a tendência é que a imigração para o Brasil só venha a crescer nos próximos anos, de modo que um marco legislativo e institucional adequado para lidar com as migrações internacionais é, mais do que nunca, fundamental. Do ponto de vista moral, por uma questão de respeito aos direitos humanos dos imigrantes; do ponto de vista doméstico, para evitar o surgimento de problemas sociais e políticos de maiores proporções e de solução mais complicada; e, finalmente, do ponto de vista da política externa, porque o tema da gestão das migrações internacionais é e continuará sendo central no plano das relações internacionais ainda por muitos anos.

\section{Notas}

1 Marcia Anita Sprandel (2010) argumenta que os brasiguaios na década de 1970 foram pioneiros nesse tipo de organização. De maneira semelhante, Bela Feldman-Bianco (2010) argumenta que a Casa do Brasil, fundada por emigrantes brasileiros em Portugal, teve um papel de destaque na articulação das demandas dos brasileiros no exterior na história mais recente.

2 Disponível em: < http://www.rede-brasileira.eu/atividades/1_encontro_bra sileiros_lisboa/1_encontro_brasileiro.html>. Acesso em: ago. 2011. 


\section{Rossana Rocha Reis}

3 No primeiro semestre de 2010, os brasileiros foram o grupo nacional mais barrado nos aeroportos da Europa (1.842 pessoas entre janeiro e março), de acordo com dados da Frontex (Agência Europeia de Controle das Fronteiras), disponíveis em: <http://www.frontex.europa.eu>. Acesso em: ago. 2011.

4 Disponível em: <http://www.senado.gov.br/atividade/comissoes/comissao. asp?origem $=\mathrm{CN} \&$ com $=1330>$. Acesso em: ago. 2011.

5 Disponível em: <sistemas.mre.gov.br>. Acesso em: jan. 2011.

6 Já existe uma proposta de emenda constitucional que incorpora essa sugestão.

7 Proposta incorporada ao projeto de lei PLS47/06, de autoria do deputado Valdir Raupp. Além disso, existem diferentes iniciativas parlamentares voltadas para os brasileiros no exterior, para a criação da "poupança emigrante" e do "fundo de financiamento ao emigrante empreendedor" (PLS 74/04).

8 Também existe um conjunto de políticas públicas voltadas especificamente para a população que vive nas fronteiras, como a recente criação do Sistema Integrado de Saúde das Fronteiras, o SIS Fronteiras, que tem como objetivo fortalecer os sistemas de saúde dos municípios localizados nas fronteiras, e em médio prazo contribuir para a integração regional por meio de acordos e ações multilaterais e bilaterais.

9 Discurso (não publicado) realizado na $35^{\mathrm{a}}$ Cúpula dos Chefes de Estado do Mercosul em Tucumán, Argentina, em $1^{\text {o }}$ de julho de 2008.

\section{Referências} Bibliográficas

ABDALA, Vitor. Lula diz que Brasil está aberto aos imigrantes. A Tarde, 28 mai. 2010. Disponível em: <http://www.atarde.com.br/politica/noticia.jsf?id= 2535914>. Acesso em: 28 mai. 2010.

ACNUR; IMDH; CDHM. Políticas públicas para as migrações Internacionais. Migrantes e refugiados. 2 ed. revista e atualizada. Brasília: ACNUR; IMDH; CDHM, 2007. 
AMORIM, Celso. Mensagem do ministro das Relações Exteriores. Informe MRE Comunidades Brasileiras no Exterior, n. 1, 28 jul. 2009.

CHELIUS, Leticia Mora Calderón. Redefinindo a geografia política nacional: sobre a participação política dos cidadãos brasileiros no exterior. In: MALHEIROS, Jorge. Imigração brasileira em Portugal. Lisboa: ACIDI, 2007.

FELDMAN-BIANCO, Bela. O Brasil como país de emigração: mobilizações e políticas. In: FERREIRA, A. P. et al. A experiência migrante. Entre deslocamentos e reconstruções. Rio de Janeiro: Ed. Garamond, 2010.

FUNAG - Fundação Alexandre Gusmão. Brasileiros no mundo. Diretório das comunidades de brasileiros no exterior. Brasília. Fundação Alexandre Gusmão, 2009.

ITAMARATY cria canal direto com brasileiros que vivem fora do país. Rede Brasil Atual, 8 dez. 2010. Disponível em: <http://www.redebrasilatual.com.br/ temas/cidadania/2010/12/2010/12/itamaraty-cria-canal-direto-com-brasileirosque-vivem-fora-do-pais>. Acesso em: ago. 2011.

LULA: "Desemprego não é culpa dos imigrantes pobres". UOL Notícias, 15 jun. 2009a. Disponível em: <http://noticias.uol.com.br/bbc/2009/06/15/ult5017u219. jhtm>. Acesso em: ago. 2011.

LULA sanciona lei que anistia estrangeiros em situação ilegal. O Estado de $\mathbf{S}$. Paulo, 2 jul. 2009b. Disponível em: < http://www.estadao.com.br/noticias/ nacional,lula-sanciona-lei-que-anistia-estrangeiros-em-situacao-ilegal,396948,0.htm>. Acesso em: ago. 2011.

MILESI, Rosita; BARBOSA, Luciano. Integração dos nacionais do Mercosul, Bolívia e Chile já é realidade. Brasília: Instituto Migrações e Direitos Humanos, 2009.

MRE - Ministério das Relações Exteriores. Brasileiros no mundo. Estimativas. Brasília: Ministério das Relações Exteriores, 2008.

Informe n. 11. Brasília: MRE, 24 mai. 2010.

. Serviço Consular Brasileiro. Consulados itinerantes em 2010 - Dados

estatísticos. s/d. Disponível em: <http://www.portalconsular.mre.gov.br/avisos /servico-consular-brasileiro $>$. Acesso em: 12 jan. 2011. 
OIM; CNPD; MINISTÉRIO DO TRABALHO E EMPREGO. Perfil migratório do Brasil 2009. Genebra: OIM, 2010. Disponível em: $<$ http://publications.iom.int /bookstore/free/Brazil_Profile2009.pdf>. Acesso em: ago. 2011.

PATARRA, Neide. Emigração e imigração internacionais no Brasil contemporâneo. São Paulo: FNUAP, 1996.

PRESIDÊNCIA DA REPÚBLICA. Decreto n ${ }^{\circ} 840$, de 22 de junho de 1993. Brasília, 1993. Disponível em: <http://www.oas.org/dil/Migrants/Brasil /Decreto\%20No\%20840,\%20de\%2022\%20de\%20junho\%20de\%201993.pdf $>$. Acesso em: 22 set. 2011.

REPÚBLICA FEDERATIVA DO BRASIL. Congresso Nacional. Comissão Parlamentar Mista de Inquérito da Emigração. Relatório final da Comissão Parlamentar Mista de Inquérito. Brasília, 2006. Disponível em: $<$ http://www.diasmarques.adv.br/artigos/Relatorio_CPI_Emigracao_Ilegal.pdf $>$. Acesso em: 22 set. 2011.

SALES, Teresa. Brasileiros longe de casa. São Paulo: Ed. Cortez, 1999.

SPRANDEL, Marcia Anita. Breve análise da relação entre o Estado brasileiro e seus emigrantes. In: FERREIRA, A. P. et al. A experiência migrante. Entre deslocamentos e reconstruções. Rio de Janeiro: Ed. Garamond, 2010.

\section{Resumo}

\section{A Política do Brasil para as Migrações Internacionais}

O objetivo deste artigo é analisar a maneira como o Estado brasileiro vem se posicionando em relação às migrações internacionais, e seu comportamento em relação aos fluxos migratórios contemporâneos que envolvem o país. Ao longo dos últimos vinte anos, o Brasil adotou uma série de novas políticas voltadas ao atendimento dos brasileiros no exterior, à gestão dos movimentos transfronteiriços e aos imigrantes no Brasil, políticas estas que respondem não somente ao ativismo dos migrantes e seus aliados, mas também à estratégia da política externa brasileira, sobretudo ao longo do governo Lula. Nos últimos anos, as migrações inter- 
nacionais despontam como um tema estratégico para as relações internacionais no século XXI, e o Estado brasileiro tem explorado a questão como uma plataforma para criticar determinados países e demandar mudanças na ordem internacional.

Palavras-chave: Política de Migração - Migrações Internacionais - Política Externa

\section{Abstract}

\section{Brazilian Policy for International Migrations}

The purpose of this article is to analyze how the Brazilian State has positioned itself with respect to the international migration, and to analyze its behavior regarding contemporary migratory flows involving the country. Over the last twenty years, Brazil has adopted a set of new policies concerning the treatment of Brazilians abroad and the management of the cross-borders movements, including the issue of immigrants in Brazil. These policies not only respond to the activism of migrants and their partners, but also reflect the strategy of Brazilian foreign policy, mainly conducted during the Lula administration. In recent years, international migration has become a strategic issue in the international relations' agenda of the twenty-first century, and Brazil has engaged with this question as a basis to criticize some countries and to demand changes in the international order.

Keywords: Migration Policy - International Migrations - Foreign Policy 